\title{
Analisis Swot Strategi Pengembangan Asuransi Syariah Bumiputera di Aceh
}

\author{
Nilam Sari ${ }^{1 *)}$, Hafiizh Maulana ${ }^{2)}$, Mirza Frananda Kusuma ${ }^{3)}$ \\ ${ }^{1,2,3}$ Fakultas Ekonomi dan Bisnis Islam, UIN Ar-raniry Banda Aceh \\ *Email Korespondensi : nilam.sari@ar-raniry.ac.id
}

\section{Abstract}

The study, entitled "SWOT Analysis development Strategy Of Sharia Insurance Bumiputera in Aceh ", aims to find out the development of Bumiputera Islamic insurance in Aceh Province and the strategy for developing the Syari'ah Bumiputera insurance in Banda Aceh City. This study uses a non-experimental quantitative descriptive approach. Data collection techniques by interview and documentation. Data analysis using SWOT analysis. Based on the research results, it is known that the potential of PT. In terms of strength, the Banda Aceh branch of Syari'ah Bumiputera Insurance is the principle of non-usury, the network is online, the general takaful is full of sharia, the brand is stronger as sharia insurance than other sharia insurance companies, the policy is quickly completed and the claims service is served well. Opportunities are that the majority of Banda Aceh's residents are Muslim, sharia banking is growing and advances in technology (internet). Constraints owned by PT. In terms of weaknesses, the Banda Aceh branch of Syari'ah Bumiputera Insurance is that the market share of Islamic insurance in Aceh is still low and quality human resources are still limited. Threats are the amount of competition in the insurance industry, then a lack of public understanding of the capital regulation syari'ah insurance. Strategies that can be implemented or utilized by PT. Asuransi Syari'ah Bumiputera Banda Aceh branch is a strategy of Strengths Opportunities. The strategy is to optimize the coverage area with agent support, increase and maintain cooperation with the syari'ah banking industry and increase flexibility in the claim processing mechanism.

Keywords: Development Strategy, Syari'ah Insurance, Bumiputera SWOT Analysis

Saran sitasi: Sari, N., Maulana, H., \& Kusuma, M. F. (2021). Analisis Swot Strategi Pengembangan Asuransi Syariah Bumiputera di Aceh. Jurnal Ilmiah Ekonomi Islam, 7(01), $130-134$. doi:http://dx.doi.org/10.29040/jiei.v7i1.1442

DOI: $\underline{\text { http://dx.doi.org/10.29040/jiei.v7i1.1442 }}$

\section{PENDAHULUAN}

Asuransi merupakan pertanggungan diantara dua pihak ataupun lebih dari itu, yang mana suatu pihak sebagai penanggung memiliki ikatan asuransi gunanya untuk pemberian pergantian terhadap tertanggung atas kerugian, hilangnya keuntungan yang diharapkan. Ataupun merupakan tanggung jawab pihak yang ketiga atas derita yang ditimbulkan dari peristiwa yang mungkin terjadi dan memberikan bayaran didasarkan atas hidup atau atau wafatnya orang yang telah ditanggungkan. Pertumbuhan asuransi syariah di Aceh juga masih tergolong dalam tingkatan yang masih rendah sejak awal berdirinya PT. Asuransi Takaful Keluarga(ATK), PT. Bumiputera Syariah, PT. Prudensial, PT. Asuransi AIA Syariah yang dilihat pertumbuhannya hanya $50 \%$ dari angka pencapaian target perusahaan(Jalaluddin, 2019)

Kajian ini fokus pada PT. Asuransi Bumiputera Syariah yang berlokasi di jalan Tengku Daud Beurueh, Kecamatang Kuta Alam, Banda Aceh. Asuransi Bumiputera Memberikan pelayanan asuransi kepada klien Bumiputera seperti pendaftaran asuransi, klaim asuransi, mendaftar asuransi jiwa Bumiputera seperti asuransi untuk pendidikan dan beberapa produk asuransi lainnya. Asuransi Bumiputera saat ini memberikan pengelolaan asuransi syariah melalui Bumiputera syariah, yang dijalankan sesuai dengan aturan Islam (Ramadhani, 2015)

Dalam perkembangannya asuransi syariah Bumiputera di Kota Banda Aceh ini sering mengalami berbagai kendala seperti masih minimya modal yang 


\section{Jurnal Ilmiah Ekonomi Islam, 7(01), 2021, 131}

menyebabkan rendahnya penetrasi pasar asuransi syariah, SDM yang kurang Profesional, masyarakat yang tidak tahu terhadap produk asuransi syariah, belum adanya dukungan yang memadai dari masyarakat bahkan belum adanya image yang baik untuk membuat masyarakat yakin dengan keuntungan dalam menggunakan penawaran asuransi syariah oleh di PT. Asuransi Syariah Bumiputera Kota Banda Aceh.

Berdasarkan observasi awal penulis menemukan permasalahan yang menghambat perkembangan PT. Asuransi Syariah Bumiputera baik dari pihak perusahaan seperti terkait pemasaran produk yang ditawarkan dan tenaga ahli dalam marketing. Tidak hanya itu tingkat ekonomi masyarakat dan tingkat edukasi produk terhadap masyarakat juga menjadi faktor penghambat perkembangan PT. Asuransi Syariah Bumiputera.

Dari penjelasan yang telah disampaikan pada latar belakang diatas, penulis tertarik meneliti tentang Analisis SWOT Asuransi Syariah Bumiputera di Aceh dengan fokus rumusan masalah yaitu: Bagaimana perkembangan asuransi Bumiputera Syariah di Provinsi Aceh. Bagaimana strategi pengembangan yang harus ditempuh asuransi Syariah Bumiputera berdasarkan aspek produk, pemasaran, edukasi dan tingkat ekonomi masyarakat.

\section{METODE PENELITIAN}

Penulis menggunakan pendekatan deskriptif kuantitatif yang bersifat non eksperimental. (Sugiono, 2014) menyatakan bahwa penulisan secara kuantitatif ialah suatu penelitian yang meneliti populasi atau sample tertentu, penentuan sampel yang digunakan dengan cara random, kemudian data dikumpulkan mengunakan instrumen penulisan, dan menganalisis data berupa kuantitatif sehingga dapat melakukan uji hipotesis yang telah ditentukan.

Sumber data dalam penulisan ini terdiri dari data primer dan data sekunder. Menurut (Bungin, 2016) "Data yang diperoleh dalam penelitian ini terdiri atas data primer dan sekunder. Menurut (Bungin, 2016) yang dimaksud dengan data primer adalah data yang didapatkan langsung dari sumber data pertama di objek penelitian, dan hasilnya didapatkan dari wawancara dengan informan kunci. Sedangkan data sekunder yaitu yang diperoleh dari sumber kedua. Data yang digunakan dapat berupa bacaan literatur yang mempunyai keterkaitan, misalnya situs internet, majalah dan jurnal ilmiah.
Menurut (Koentjaraningrat, 1997), metode wawancara mencangkup "Cara yang digunakan jika seseorang bertujuan melakukan tugas penelitian tertentu, memperoleh data lisan responden, cara berkomunikasi bertatap muka dengan responden". Cara wawancara dalam hal ini dilakukan dengan: penulis akan melakukan wawancara terbuka secara mendalam dengan cara memberikan pertanyaan berkaitan dengan pengaruh mengembangkan asuransi syariah di Aceh, sebelum pertanyaan yang ditujukan kepada informan, dipersiapkan instrumen wawancaranya dalam bentuk list pertanyaan, dibantu dengan perlengkapan wawancara seperti tape recorder supaya data wawancara didapatkan secara dan utuh.

(Suwandi, 2008) mendefinisikan metode dokumentasi adalah cara mengumpulkan data dengan tujuan menghasilkan catatan penting dan adanya hubungan masalah penelitian, sampai akhirnya data yang didapat sah dan dapat dipertanggungjawabkan". Dokumentasi yang dilaksanakan pada penulisan ini berkaitan dengan perkembangan asuransi syariah di Aceh, menelaah informasi dari sumber data seperti jurnal, buku dan akses internet berkaitan dengan asuransi syariah agar adanya solusi maupun gagasan pemikiran untuk memecahkan permasalahan.

Analisa data dalam meneliti permasalahan ini menggunakan pendekatan analisis SWOT. Analisis ini digunakan untuk mengidentifikasi faktor secara rinci dan sistematis guna merumuskan strategi perusahaan, sehingga diketahui kelemahan, peluang, ancaman maupun kekuatan yang ada. Oleh karena itu, identifikasi penyebab yang ada menggunakan matriks IFE dan EFE terlebih dahulu. Matrik ini akan menggambarkan faktor mana yang paling berpengaruh maupun yang kurang berpengaruh.

(Choirunnisak, 2012) SWOT didefnisikan dengan: S (strength) melihat pada keunggulan kompetitif, W (weakness) kendala membatasi opsional strategi dalam mengembangkan, $\mathrm{O}$ (opportunity) memberikan keadaan yang menguntungkan, memberikan peluang dan mengurangi penghalang, $\mathrm{T}$ (threat) yaitu ancaman dalam mencapai tujuan atau kondisi yang dapat menghalangi. Matriks yang telah dijelaskan diatas memberikan empat alternatif strategi yang memungkinkan, yaitu strategi S-O, strategi W-O, strategi W-T dan strategi S-T.matriks.

Pemerolehan hasil dari keadaan internal maupun eksternal ini memperlihatkan klasifikasi penyebab 


\section{Jurnal Ilmiah Ekonomi Islam, 7(01), 2021, 132}

atau faktor berupa; Strenght, weakness, opportunity, threat. Hasil yang didapatkan ini dianalisis menggunakan analisis matriks SWOT, caranya yaitu dengan melakukan penggabungan atau merger faktor internal yaitu strength dan weakness dengan faktor eksternal yaitu opportunity, dan threat. (Rangkuti, 2013)

\section{HASIL DAN PEMBAHASAN Hasil}

Kondisi personalia merupakan suatu keadaan yang menjelaskan tata cara kerja ataupun karyawan di sebuah perusahaan sampai kegiatan perusahaanya dapat berjalan dengan lancar, dengan tujuan agar setiap bagian dapat melakukan tanggungjawabnya dengan baik. Demikian juga halnya di Asuransi Bumiputera Syariah.

Petugas yang ada di Asuransi Bumiputera Syariah Cabang Banda Aceh berjumlah 27 orang, yang ditempatkan pada bagian yang berbeda. Kondisi personalia di Asuransi Bumiputera Syariah Cabang Banda Aceh berupa posisi kerja serta jumlah karyawan setiap bidangnya. Posisi karyawan pada masing-masing bagian Asuransi Syariah Bumiputera Banda Aceh dapat dilihat pada tabel berikut ini.

Tabel 1.1 Jumlah Karyawan Asuransi Syariah Bumiputera Banda Aceh

\begin{tabular}{|c|l|c|}
\hline No. & \multicolumn{1}{|c|}{ Posisi Kerja } & Jumlah \\
\hline 1 & Kepala Cabang & 1 \\
\hline 2 & $\begin{array}{l}\text { Kepala Unit Administrasi dan } \\
\text { Keuangan (K.U.A.K) }\end{array}$ & 1 \\
\hline 3 & Kasir & 1 \\
\hline 4 & Staff Produksi dan Klaim Askum & 2 \\
\hline 5 & Bagian Konservasi dan Klaim Asper & 2 \\
\hline 6 & Bagian SDM dan Umum & 1 \\
\hline 7 & Office Boy & 1 \\
\hline 8 & Supervisor & 3 \\
\hline 9 & Agen Total & 15 \\
\hline \multicolumn{2}{|c|}{ Tot } \\
\hline
\end{tabular}

Sumber: Bumiputera Syariah Cabang Banda Aceh, 2018

Asuransi Bumiputera Syariah Banda Aceh dibantu oleh 27 karyawan yang ada disetiap bagian posisi kerja terdiri dari 19 pria dan 8 wanita. Asuransi Bumiputera Syariah mempunyai struktur organisasi yaitu 1 pimpinan, 1 Ketua Unit Administrasi dan Keuangan, 1 kasir, 2 staff produksi dan Klaim Askum, 2 konservasi dan Klaim Asper, 1 bidang umum, 1 office boy, 3 supervisor serta 15 petugas Agen.
Asuransi Bumiputera Syariah Banda Aceh memiliki upaya dalam melakukan pengembangan perusahaannya dari beberapa aspek di antaranya pemasaran, tingkat ekonomi masyarakat, edukasi, dan produk.

Dilihat dari aspek produk, Asuransi Syariah Bumiputera Banda Aceh melaksanakan strategi pengembangan dengan cara melakukan pengadaan di berbagai produk untuk nasabah. Jenis produk itu seperti asuransi jiwa individu dan asuransi jiwa group.

Produk dari Mitra Iqra' Plus yaitu perancangan yang dibuat khusus untuk mitra pelajar. Pelajar akan mendapatkan dana pendidikan dan disesuaikan dengan jenjang pendidikannya. Tidak hanya itu, mereka juga memperoleh hasil dari investasi yang diperoleh melalui sistem bagi hasil (muḍārabah). Mitra Iqra Plus ini dibuat khusus bagi mitra pelajar seperti anak yang sedang dalam pendidikan.

Mitra Mabrur Plus juga membantu mencapai keinginan seseorang agar dapat mengunjungi Mekkah Baitullah, untuk menunaikan ibadah haji. Mitra Mabrur Plus ini, selain membantu mitra dalam dana tabungan haji, juga memberikan dana bagi mitra dari hasil kegiatan muḍhārabah dan juga mendapat asuransi perlindungan, agar peserta menunaikan ibadah haji dalam keadaan khusyuk.

Mitra Amanah yaitu memberikan solusi dalam rencana keuangan yang lebih bermanfaat. Mitra Amanah merupakan produk asuransi dibidang kesehatan, mitra amanah ini unit link pertama Asuransi Bumiputera Syariah di bagian kesehatan.

Asuransi kumpulan merupakan asuransi yang menyediakan perlindungan murni atas resiko kematian selama satu tahun dan ini tidak termasuk tabungan, jika peserta hidup hingga masa asuransi peserta berakhir, tidak ada mendapatkan bayaran apapun untuknya.

Masa Depan Cerah Dengan Investasi dan Proteksi Maksimal Mitra BP-Link (Bumiputera Link) Syariah merupakan asuransi tolong menolong antara pihak penanggung dan anggota dalam hal mengurangi risiko finansial maupun keuangan yang diakibatkan karena adanya musibah kematian.

PT. Asuransi Syariah Bumiputera di Aceh dapat melihat kondisi internal maupun eksternal dalam mengembangkan perusahaan dengan melihat secara internal maupun eksternal perusahaan. Pemerolehan data dari wawancara dengan pimpinan PT. Asuransi Syariah Bumiputera cabang Banda Aceh, maka 


\section{Jurnal Ilmiah Ekonomi Islam, 7(01), 2021, 133}

dengan ini dapat diidentifikasikan faktor internal dan eksternal dalam mengembangkan Lembaga.

\section{Pembahasan}

Ada beberapa keunggulan yang mendukung strategi dalam mengembangkan PT. Asuransi Syariah Bumiputera Cabang Banda Aceh (Ramadhani, 2015), di keunggulan tersebut diantaranya: Didasarkan atas prinsip non Riba, pelayanan tidak mengandung riba, gharar dan terhindar dari pelanggaran syariat agama Islam (Muhaimin dan Abdul Mujib, 1993). Pelayanan yang diberikan juga sudah ada dalam jaringan online dan telah memanfaatkan berbagai teknologi informasi berupa jaringan online seperti dalam memberikan informasi kepada publik maupun melakukan pelayanan secara online. PT Asuransi Syariah Bumi sudah menerapkan full syariah, sudah secara keseluruhan memakai prinsip syariah baik dari segi pelayanan, penawaran produk maupun dalam melakukan strategi pengembangannya(Priangani, 2013).

Brand asuransi syariah sudah termasuk kuat jika dibandingkan dengan perusahaan asuransi syariah yang lain. PT. Asuransi Syariah Bumiputera Cabang Banda Aceh dalam proses pelayanan cepat sehingga tidak menyulitkan para nasabah, nasabah dimudahkan ketika mengurus polis asuransi saat hendak menjadi nasabah PT. Asuransi Syariah Bumiputera Cabang Banda Aceh. Tanggap melayani klaim nasabah dengan baik. Karyawan dalam Pelayananan yang diberikan sangat ramah, sopan dan santun. Selain itu , terdapat Dewan Pengawas Syariah yang bertugas secara khusus mengawasi berbagai kegiatan PT. Asuransi Syariah Bumiputera Cabang Banda Aceh agar tidak melakukan pelanggaran terhadap nilai-nilai keislaman (Wirdyaningsih, 2017). Hal ini akan membuat masyarakat semakin yakin dengan prinsipprinsip pelayanan yang diberikan oleh PT. Asuransi Syariah Bumiputera Cabang Banda Aceh.

PT. Asuransi Syariah Bumiputera cabang Banda Aceh juga terdapat kelemahan yang harus diantisipasi (M.Hanafi, 2014), yaitu: Lemahnya Market share Asuransi Syariah di Indonesia. Masih terbatasnya Sumber Daya Manusia (SDM) yang berkualitas, artinya SDM pendukung belum sepenuhnya mengerti bisnis syariah. Adanya penambahan perusahaan asuransi syariah merupakan berita baik dalam perkembangan industri. Namun juga tidak berarti jika tidak diimbangi dengan tersedianya Sumber Daya Manusia (SDM) (Muhammad, 2001). Sekitar 80\% dari divisi asuransi syariah di Indonesia belum ada ajun ahli syariah. Hal ini akan memberikan dampak pada kurangnya perkembangan produk lembaga asuransi berbasis syariah. Sekarang ini, beberapa PT. Asuransi Syariah Bumiputera cabang Banda Aceh mencontoh produk asuransi konvensional kemudian dikonversikan ke syariah. Kurangnya sumber daya manusia, dalam hal ini dikarenakan sebagian besar dari sumber daya manusia yang ada merupakan lulusan dari program studi konvensional. Penyebab lain, yaitu masih kurang motivasi untuk mendalami segmentasi pasar dari bagian marketing. Masih kurangya promosi berbentuk iklan, maksudnya adalah berbagai produk yang disediakan oleh PT. Asuransi Syariah Bumiputera cabang Banda Aceh hanya sering dipromosikan menggunakan brosur-brosur yang terkadang didapatkan oleh masyarakat pada saat berkunjung ke kantor. Sedangkan promosi melalui iklan baik melalui TV, Chanell, Radio dan sebagainya sangat kurang dan bahkan tidak ada sama sekali. Penyebab lainnya yaitu masih kurangnya jumlah agen sehingga penetrasi Market masih terbatas.

\section{KESIMPULAN}

a. Keunggulan asuransi Bumiputera adalah menggunakan prinsip non Riba, bisa diakses melalui jaringan online. Brand syariah Bumiputera sudah lebih kuat dibandingkan asuransi syariah lainnya. Klaim dari peserta cepat tertangani serta mendapatkan pelayanan yang baik. Dari segi peluang, kebanyakan peserta warga Kota Banda Aceh beragama Islam.

b. Kendala yang dihadapi oleh asuransi syariah bumiputera adalah market share yang masih sangat minim dan terbatasnya Sumber Daya Manusia (SDM) yang berkualitas. Dari segi ancaman yaitu adanya persaingan yang sudah banyak di industri perasuransian, baik dari asuransi syariah maupun konvensional. Pemahaman masyarakat tentang asuransi syariah peraturan permodalan masih sangat kurang.

c. PT. Asuransi Syariah Bumiputera cabang Banda Aceh terdapat pada tingkatan kuadran 1. Asuransi Bumiputera menggunakan upaya SO. Upaya ini merupakan cara meningkatkan jumlah dan menjaga ikatan kerjasama dengan pihak industri perbankan berbasis syariah serta meningkatkan fleksibilitas mekanisme dalam mengurus klaim, serta mengoptimalkan jangkauan dengan adanya dukungan agen. 


\section{Jurnal Ilmiah Ekonomi Islam, 7(01), 2021, 134}

\section{DAFTAR PUSTAKA}

Bungin, B. (2016). Metodologi Penelitian Sosial dan Ekonomi. In Metodologi Penelitian.

Choirunnisak. (2012). Penerapan Analisis SWOT dalam Strategi Pemasaran. Choirunnisak (2012) "Penerapan Analisis SWOT Dalam Strategi Pemasaran Produk Tabungan Pada BMI Cabang Pembantu Magelang."

Jalaluddin, J. (2019). Faktor-faktor Yang Mempengaruhi Masyarakat Banda Aceh Dalam Pemilihan Asuransi Jiwa Syariah. Jurnal Perspektif Ekonomi Darussalam. https://doi.org/10.24815/jped.v4i1.10928

Koentjaraningrat. (1997). Metode Penelitian Masyarakat. Metode Penelitian Masyarakat.

M.Hanafi, M. (2014). Risiko, Proses Manajemen Risiko, dan Enterprise Risk Management. Management Research Review.

Muhaimin dan Abdul Mujib. (1993). Pemikiran Pendidikan Islam. In Pemikiran Pendidikan Islam.

Muhammad, M. (2001). Asuransi dalam Perspektif Hukum Islam. Jurnal Hukum IUS QUIA IUSTUM. https://doi.org/10.20885/iustum.vol8.iss18.art11

Priangani, A. (2013). Memperkuat Manajemen Pemasaran Dalam Konteks Persaingan Global. Jurnal Kebangsaan.

Ramadhani, H. (2015). Prospek dan Tantangan Perkembangan Asuransi Syariah di Indonesia. AL-TIJARY. https://doi.org/10.21093/at.v1i1.422 Rangkuti, F. (2013). Teknik Membedah Kasus Bisnis Analisis SWOT Cara Perhitungan Bobot, Rating, dan OCAI. In PT. Gramedia Pustaka Utama. Jakarta.

Sugiono, P. D. (2014). Metode penelitian pendidikan pendekatan kuantitatif.pdf. In Metode Penelitian Pendidikan Pendekatan Kuantitatif, Kualitatif Dan $R \& D$.

Suwandi, B. dan. (2008). Memahami Penulisan Kualitatif. Rineka Cipta.

Wirdya ningsih, N. (2017). Hukum Islam Dan Pelaksanaannya Di Indonesia. Jurnal Hukum \& Pembangunan.

https://doi.org/10.21143/jhp.vol31.no4.1295 